\title{
Reactivation of Hepatitis B Virus During Treatment of Hepatitis C Genotype 3 with Daclatasvir and Sofosbuvir in a Patient with Dual Infection of Hepatitis B and Hepatitis C Virus
} Georgios Zacharakis, ${ }^{1,2, *}$ and Jaman Alzahrani ${ }^{2}$

\author{
${ }^{1}$ Endoscopy Unit, Limassol General Hospital and St George's University of London Medical School at the University of Nicosia, Republic of Cyprus \\ ${ }^{2}$ Department of Internal Medicine, University Hospital, Prince Sattam Bin Abdulaziz University, Al Kharj, KSA \\ "Corresponding author: Georgios Zacharakis, Endoscopy Unit, Department of Internal Medicine, University Hospital, Prince Sattam Bin Abdulaziz University, Al Kharj, Saudi \\ Arabia. Tel: +96-65886750, E-mail: gzacharakis@yahoo.gr
}

Received 2017 May 04; Revised 2017 September 16; Accepted 2017 December 24.

\begin{abstract}
Introduction: The recent use of new direct-acting drugs (DAAs) in the treatment of chronic hepatitis C needs to be evaluated in HBV/HCV coinfected patients. Case Presentation: Here, we report the case of a 47-year-old female patient with HBV/HCV coinfection who experienced HBV reactivation during treatment with daclatasvir (DCV) and sofosbuvir (SOF). In addition to the DAAs, Entecavir (ETV) was added to the combined regimen with improvement in ALT levels.

Conclusions: Both HBV and HCV treatment could be implemented effectively in case of reactivation of HBV during anti-HCV treatment with DAAs. Close monitoring of HBV DNA and ALT levels are highly recommended during DAAs drug therapy for HCV in patients with HBV/HCV dual infection.
\end{abstract}

Keywords: Hepatitis B, Hepatitis C, Coinfection, HCV Direct Acting Antivirals, Nucleos(t)ide Analogues, HBV Reactivation

\section{Introduction}

Both chronic hepatitis B (HBV) and chronic hepatitis C (HCV) infections are major public health issues globally (1). The primary concern is HBV and HCV co-infection that results in a more severe liver disease progression compared to mono-infections (2-4), with an increased risk of hepatocellular cancer (HCC) (5-7) and of fulminant hepatitis (8). New findings confirmed that HBV/HCV coinfected patients might experience more rapid progression of severe liver disease compared to those with hepatitis B alone although similar data for Asian and African patients with the highest prevalence of HBV infection worldwide are still missing (9). Furthermore, co-infection did not worsen HCV liver disease progression in the same study (9). Nevertheless, treatment should be prioritized for HCV/HBV dually infected patients to avoid severe liver disease progression (10). Recently published recommendations from both the European Association for the Study of the Liver (EASL) and the American Association for the Study of Liver Diseases (AASLD) suggest that the same therapeutic criteria should be applied to patients who are co-infected based on the viral dominance after hepatitis $B$ and $C$ viral interactions as applied to patients with either HBV or HCV monoinfection $(10,11)$. The introduction of new directacting drugs (DAAs) has brought new therapeutic options in treating HCV although they need to be evaluated in coinfected patients with hepatitis B and C viruses. Neverthe- less, it seems reasonable as a first-line therapy based on existing data for DAAs therapies in HCV mono-infected patients. A shift to a nucleos(t)ide analogue with high potency and high genetic barrier for patients with HBV DNA persistence should always be considered. Rarely, both HBV and HCV treatments could be implemented in case of reactivation of hepatitis B virus during anti-HCV treatment or after treatment or synchronously active HBC/HCV infection (10). However, the risk of HBV reactivation during DAAs-based anti-HCV treatment in HBV/HCV co-infection is unpredictable and needs to be evaluated. Here, we report the case of a 47-year-old female patient with HBV/HCV coinfection who experienced HBV reactivation during treatment with daclatasvir (DCV) and sofosbuvir (SOF).

\section{Case Presentation}

A 47-year-old female patient with $\mathrm{HBV} / \mathrm{HCV}$ coinfection, known since 1993 of Limassol General Hospital, presented to our outpatient gastroenterology clinic for treatment. There was no history of previous treatment. She had HCV Genotype 3 with serum levels of alanine aminotransferase (ALT) of $112 \mathrm{U} / \mathrm{L}, \gamma$-glutamyltransferase $53 \mathrm{U} / \mathrm{L}$, bilirubin 1.1 $\mathrm{mg} / \mathrm{dL}, \mathrm{HBs} A g$ 1.1 $\log \mathrm{IU} / \mathrm{L}$ anti-HBc total $2.9 \log \mathrm{U} / \mathrm{mL}$, antiHBc IgM negative, anti-HBe positive, serum HCV-RNA 4.8 $\log \mathrm{IU} / \mathrm{mL}$, and serum HBV HBV-DNA of $1.1 \log \mathrm{IU} / \mathrm{mL}$. Liver ultrasound was negative for cirrhosis findings. Fibroscan revealed liver stiffness measurement $11 \mathrm{KPa}$. 
HCV treatment with DCV (400 mg) and SOF (60 mg) daily for 12 weeks started because of moderate liver fibrosis (liver stiffness measurement: $11 \mathrm{KPa}$ ) and HCV dominance. The low serum HBV DNA levels $(<2000 \mathrm{IU} / \mathrm{mL})$ and antiHBc IgM negative serology suggested that she should be classified as a patient with HBeAg-negative chronic HBV infection, previously termed 'inactive carrier' (HBsAg positive (usually less than $1000 \mathrm{IU} / \mathrm{mL}$ ), HBeAg (-), anti-HBe $(+)$, very low or undetectable serum HBV DNA levels (< $2.000 \mathrm{IU} / \mathrm{mL}$, occasionally $<20.000 \mathrm{IU} / \mathrm{mL}$ ), and normal serum aminotransferases (12). Thus, HBV treatment was not thought to be necessary for her according to a recent publish by EASL clinical practice guidelines on the management of hepatitis B virus infection (12).

During HCV treatment, close monitoring of serum ALT showed a gradual increase that reached 123 U/L on week 6 although HCV RNA levels were undetectable. Serum HBV DNA was increasing to $6.0 \log \mathrm{IU} / \mathrm{mL}$ at week 6 . Anti-HBc IgM became positive at week 4 . Total Bilirubin was always less than $3 \mathrm{mg} / \mathrm{dL}$. Entecavir ( $0.5 \mathrm{mg}$ daily) was added to the combined regimen with improvement in ALT levels.

Table 1. Laboratory Data Before Initiation of Treatment

\begin{tabular}{lc}
\hline Variables & Value \\
\hline WBCs & $6.7 \times 10^{9} / \mathrm{L}$ \\
\hline Hb & $12.4 \mathrm{~g} / \mathrm{dL}$ \\
\hline PLT & $16.7 \times 10^{9} / \mathrm{L}$ \\
\hline PT/INR & $91 / 1.1 \mathrm{~s}$ \\
\hline Albumin & $4.1 \mathrm{~g} / \mathrm{dL}$ \\
\hline Total bilirubin & $1.1 \mathrm{mg} / \mathrm{dL}$ \\
\hline AST/ALT & $98 / 112 \mathrm{U} / \mathrm{L}$ \\
\hline gGT & $53 \mathrm{U} / \mathrm{L}$ \\
\hline HBsAg & + \\
\hline HBeAg & + \\
\hline Anti-HBe & + \\
\hline Anti-HBc total & + \\
\hline Anti-HBc IgM & + \\
\hline Anti-HCV & + \\
\hline HCV genotype & + \\
\hline HCV-RNA levels & + \\
\hline
\end{tabular}

\section{Discussion}

In real life, the alternating replicative patterns of both viruses in coinfected $\mathrm{HBV} / \mathrm{HCV}$ patients have a clinical impact. This is often because one of the viruses is replicating at a much faster rate, inhibiting the replication of the other. Indeed, in some patients with HBV/HCV dual infection after eradication of the dominant virus such as clearance of serum HCV RNA with pegylated interferon- $\alpha$ (pegIFN- $\alpha$ ) and ribavirin (RBV), the other virus then may become active (HBV reactivation) $(13,14)$. Furthermore, reactivation of hepatitis $B$ during the recent use of DAAs in the treatment of hepatitis $\mathrm{C}$ in dual $\mathrm{HBV} / \mathrm{HCV}$ infections seems to be a challenge.

Indeed, few interesting cases of $\mathrm{HBV}$ reactivation with the DAAs for HCV therapy have been recently reported. In the study of Takayama et al. (15), a dually infected patient initially received treatment with asunaprevir and daclatasvir for the HCV dominance, resulting in HCV early virological response; but the increase of serum HBV DNA levels required the use of a nucleoside analogue such as entecavir. We report a similar recent case of $\mathrm{HBV}$ reactivation of a patient coinfected with hepatitis $B$ and $C$ genotype 3 during treatment with Daclatasvir and Sofosbuvir as shown in Figures 1 and 2.

Another case also has shown early HBV reactivation during HCV treatment with the DAAs ledipasvir and sofosbuvir. The patient with past HBV infection had chronic hepatitis C infection (HCV genotype 4) and HIV coinfection (16).

Finally, similar three other cases of HBV reactivation were reported during HCV treatment with DAAs (sofosbuvir/simeprevir) in patients with HBV and HCV genotype 1 coinfections $(17,18)$. These three patients had a history of past treatment of their HCV infection with peginterferon/ribavirin without virological response. One patient was an inactive HBV carrier (serum HBV DNA levels $<2000 \mathrm{IU} / \mathrm{mL}$ or undetectable and normal serum aminotransferases), one had occult hepatitis B(HBsAg(-)and very low serum HBV DNA levels), and the last one had a past infection (HBsAg (-), anti-HBc (+), anti-HBs $( \pm)$, and undetectable serum HBV DNA levels). During anti- HCV treatment, serum HBV DNA levels increased and subsequently a nucleos(t)ide analogue (tenofovir, emtricitabine or entecavir) was added. However, one patient had liver transplantation because of fulminant hepatic failure despite the addition of nucleos(t)ide analoque.

There has been also one report of HBV reactivation with the triple therapy of peginterferon- $\alpha$, ribavirin, and simeprevir in a patient with $\mathrm{HBV} / \mathrm{HCV}$ coinfection. Entecavir was administered in addition to triple anti-HCV treatment and serum HBV DNA levels became undetectable (19).

Overall, for the period from November 2013 to October 2016, the US food and drug administration (FDA) reported 29 cases of $\mathrm{HBV}$ reactivation in patients with dual HCV/HBV infection who received DAAs regimens as anti-HCV therapy (20). As a result, FDA now issued a warning about the risk of $\mathrm{HBV}$ reactivation in those patients who are going to be treated with DAAs. 
Figure 1. Serum HBV DNA and HCV RNA Levels During Combination Therapy with DCV+SOF for a Patient with HBV/HCV-geno-3 Co-Infection and 12 Weeks Post-Treatment

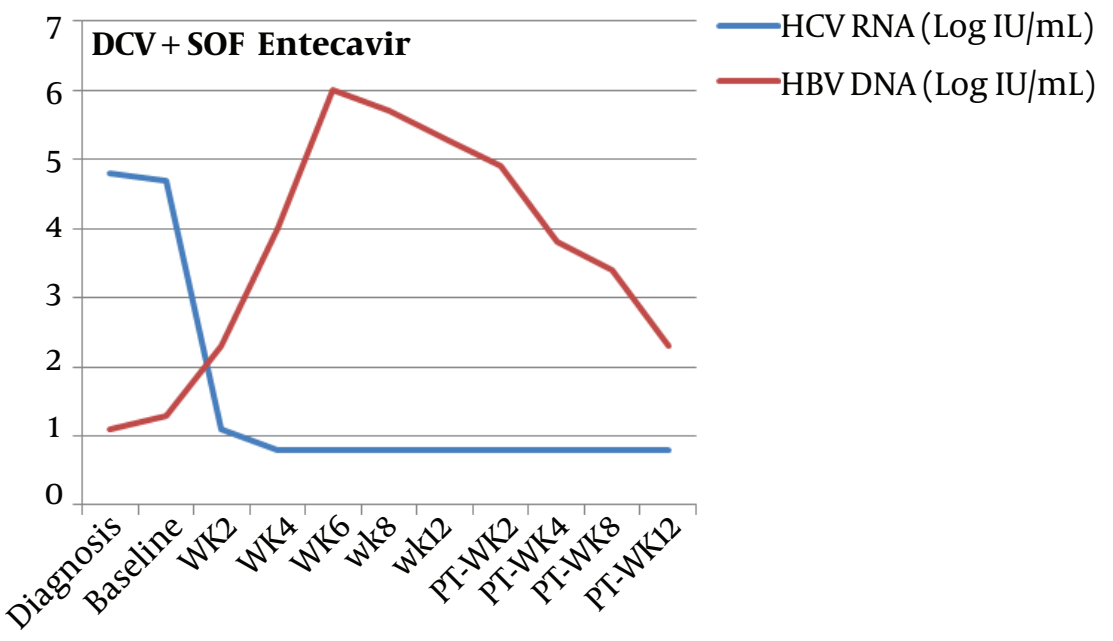

At baseline, the patient was positive for HBsAg and anti-HCV. Serum HCV RNA levels were 4.7 logIU/mL and low HBV DNA levels were 1.3 logIU/mL. After treatment with the combined regimens, serum HCV RNA levels declined. However, when HCV RNA became undetectable, HBV DNA began to rise and entecavir was added (week 6).

Figure 2. Graphical Illustration of HBV Reactivation

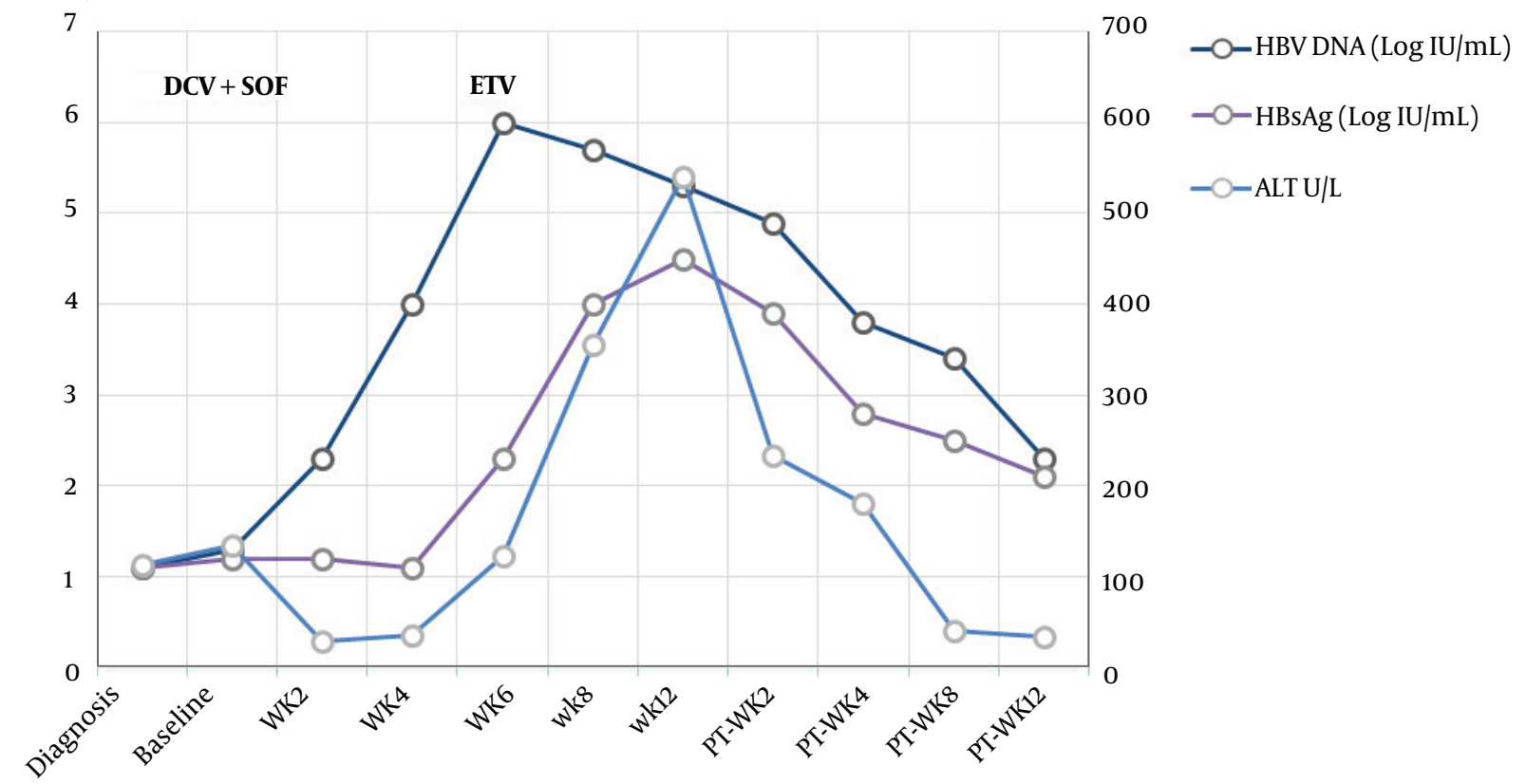

HBV DNA levels, HBsAg, and ALT over time during combination therapy with DCV + SOF for a patient with HBV/HCV-geno-3 co-infection and 12 weeks post-treatment. Anti-HBc $\operatorname{IgM}(+)$ at week 4 . Total Bilirubin: always less than $3 \mathrm{mg} / \mathrm{dL}$.

Of those 29 patients, at baseline, 9 had detectable serum HBV DNA levels, 7 were HBsAg-positive and had undetectable serum HBV DNA levels, and 3 were HBsAgnegative and had undetectable HBV-DNA levels. For the re- maining 10 patients, data were not available or uninterpretable. Two deaths and 1 case of liver transplantation were reported.

Although it is now clear that there is a potential risk 
for $\mathrm{HBV}$ reactivation associated with DAAs therapy, the risk is unpredictable. One recent study reported that out of 103 patients with resolved HBV infection treated with DAAs, none experienced reactivation (21). Another study reported out of 327 patients who received DAAs as antiviral therapy, 124 were anti-HBc positive while none of them showed $\mathrm{HBV}$ reactivation (22).

In conclusion, the current EASL and ASSLD HCV treatment guidelines suggest how to monitor these coinfected patients on DAAs with an unpredictable risk of HBV reactivation although the new regimens need to be evaluated in HBV/HCV-coinfected patients $(10,11)$. Concurrent HBV nucleoside/nucleotide analogue therapy seems to be indicated because of the unpredictable risk of HBV reactivation during HCV treatment with DAAs, especially in cases with high serum HBV DNA levels before the initiation of DAAsbased HCV treatment $(10,11)$. In resolved HBV infection, serum aminotransferase levels should be monitored and upon an increase in ALT levels on treatment, a test should be implemented for HBs antigen and/or serum HBV DNA levels. Close monitoring of HBV infection is necessary.

\section{Acknowledgments}

This project was supported by Prince Sattam bin Abdulaziz University, Deanship of Scientific Research, College of Medicine.

\section{Footnote}

\section{Conflict of Interest: None Declared}

\section{References}

1. Sagnelli E, Pisaturo M, Martini S, Sagnelli C, Filippini P, Coppola N. Advances in the treatment of hepatitis B virus/hepatitis C virus coinfection. Expert Opin Pharmacother. 2014;15(10):1337-49. doi: 10.1517/14656566.2014.913571. [PubMed: 24773464].

2. Sato S, Fujiyama S, Tanaka M, Yamasaki K, Kuramoto I, Kawano S, et al. Coinfection of hepatitis $C$ virus in patients with chronic hepatitis B infection.J Hepatol.1994;21(2):159-66. doi: 10.1016/S0168-8278(05)803897. [PubMed: 7527435 ].

3. Lee LP, Dai CY, Chuang WL, Chang WY, Hou N], Hsieh MY, et al. Comparison of liver histopathology between chronic hepatitis $\mathrm{C}$ patients and chronic hepatitis B and C-coinfected patients.J Gastroenterol Hepatol. 2007;22(4):515-7. doi: 10.1111/j.1440-1746.2006.04547.x. [PubMed: 17376043].

4. Sagnelli E, Coppola N, Pisaturo M, Masiello A, Tonziello G, Sagnelli C, et al. HBV superinfection in HCV chronic carriers: a disease that is frequently severe but associated with the eradication of HCV. Hepatology. 2009;49(4):1090-7. doi: 10.1002/hep.22794. [PubMed: 19263473].

5. Zarski JP, Bohn B, Bastie A, Pawlotsky JM, Baud M, Bost-Bezeaux F, et al. Characteristics of patients with dual infection by hepatitis $B$ and $C$ viruses.J Hepatol.1998;28(1):27-33. doi:10.1016/S0168-8278(98)80198-0. [PubMed: 9537860].
6. Donato F, Boffetta P, Puoti M. A meta-analysis of epidemiological studies on the combined effect of hepatitis B and C virus infections in causing hepatocellular carcinoma. Int J Cancer. 1998;75(3):347-54 doi: 10.1002/(SICI)1097-0215(19980130)75:3lt;347::AID-IJC4gt;3.0.CO;22. [PubMed: 9455792].

7. Shi J, Zhu L, Liu S, Xie WF. A meta-analysis of case-control studies on the combined effect of hepatitis B and C virus infections in causing hepatocellular carcinoma in China. BrJCancer. 2005;92(3):607-12. doi 10.1038/sj.bjc.6602333. [PubMed: 15685242].

8. Niederau C, Lange S, Heintges T, Erhardt A, Buschkamp M, Hurter $D$, et al. Prognosis of chronic hepatitis C: results of a large, prospective cohort study. Hepatology. 1998;28(6):1687-95. doi: 10.1002/hep.510280632. [PubMed: 9828236].

9. Pol S, Lucier S, Fontaine H, Dorival C, Petrov-Sanchez V, Bourlière M, et al. P0468: Negative impact of HBV/HCV coinfection on HBV or HCV monoinfection: Data from the French cohort - ANRS CO22 hepather.J Hepatol. 2015;62:488-9. doi: 10.1016/s0168-8278(15)30676-0.

10. European Association for the Study of the Liver. Electronic address EEE. EASL Recommendations on Treatment of Hepatitis C 2016. J Hepatol. 2017;66(1):153-94. doi: 10.1016/j.jhep.2016.09.001. [PubMed: 27667367].

11. Aasld Idsa Hcv Guidance Panel . Hepatitis C guidance: AASLDIDSA recommendations for testing, managing, and treating adults infected with hepatitis C virus. Hepatology. 2015;62(3):932-54. doi: 10.1002/hep.27950. [PubMed: 26111063]

12. Lampertico P, Agarwal K, Berg T, Buti M, Janssen HLA, Papatheodoridis G. EASL 2017 Clinical Practice Guidelines on the management of hepatitis B virus infection. J Hepatol. 2017;67(2):370-98.

13. Potthoff A, Wedemeyer H, Boecher WO, Berg T, Zeuzem S, Arnold J, et al. The HEP-NET B/C co-infection trial: A prospective multicenter study to investigate the efficacy of pegylated interferonalpha2b and ribavirin in patients with $\mathrm{HBV} / \mathrm{HCV}$ co-infection. J Hepatol. 2008;49(5):688-94. doi: 10.1016/j.jhep.2008.03.028. [PubMed: 18490077].

14. Hamzaoui L, El Bouchtili S, Siai K, Mahmoudi M, Azzouz MM. Hepatitis B virus and hepatitis C virus co-infection: a therapeutic challenge. Clin Res Hepatol Gastroenterol. 2013;37(1):e16-20. doi 10.1016/j.clinre.2012.08.001. [PubMed: 22959099].

15. Takayama H, Sato T, Ikeda F, Fujiki S. Reactivation of hepatitis B virus during interferon-free therapy with daclatasvir and asunaprevir in patient with hepatitis B virus/hepatitis C virus co-infection. Hepatol Res. 2016;46(5):489-91. doi: 10.111//hepr.12578. [PubMed: 26297529].

16. De Monte A, Courjon J, Anty R, Cua E, Naqvi A, Mondain V, et al. Direct-acting antiviral treatment in adults infected with hepatitis $C$ virus: Reactivation of hepatitis B virus coinfection as a further challenge. J Clin Virol. 2016;78:27-30. doi: 10.1016/j.jcv.2016.02.026. [PubMed: 26967675].

17. Collins JM, Raphael KL, Terry C, Cartwright EJ, Pillai A, Anania FA, et al. Hepatitis B Virus Reactivation During Successful Treatment of Hepatitis C Virus With Sofosbuvir and Simeprevir. Clin Infect Dis. 2015;61(8):1304-6. doi: 10.1093/cid/civ474. [PubMed: 26082511].

18. Ende AR, Kim NH, Yeh MM, Harper J, Landis CS. Fulminant hepatitis B reactivation leading to liver transplantation in a patient with chronic hepatitis $C$ treated with simeprevir and sofosbuvir: a case report. J Med Case Rep. 2015;9:164. doi: 10.1186/s13256-015-0630-8. [PubMed: 26215390].

19. Kimura H, Ohkawa $K$, Sakakibara M, Imanaka $K$, Matsunaga $T$, Miyazaki M, et al. Sustained hepatitis C virus RNA clearance accompanied by elevation of hepatitis B virus DNA after short-term peginterferon- $\alpha$, ribavirin and simeprevir therapy in a chronic hepatitis patient having dual infection with hepatitis B and C viruses. Kanzo. 2015;56(8):422-7. doi: 10.2957/kanzo.56.422.

20. Bersoff-Matcha SJ, Cao K, Jason M, Ajao A, Jones SC, Meyer T, et al Hepatitis B Virus Reactivation Associated With Direct-Acting Antiviral Therapy for Chronic Hepatitis C Virus: A Review of Cases Reported to the U.S. Food and Drug Administration Adverse Event Reporting System. Ann Intern Med. 2017;166(11):792-8. doi: 10.7326/M170377. [PubMed: 28437794].

Hepat Mon. 2018; 18(1):e12531. 
21. Sulkowski MS, Chuang WL, Kao JH, Yang JC, Gao B, Brainard DM, et al. No Evidence of Reactivation of Hepatitis B Virus Among Patients Treated With Ledipasvir-Sofosbuvir for Hepatitis C Virus Infection. Clin Infect Dis. 2016;63(9):1202-4. doi: 10.1093/cid/ciw507. [PubMed: 27486112].
22. Wang C, Ji D, Chen J, Shao Q, Li B, Liu J, et al. Hepatitis due to Reactivation of Hepatitis B Virus in Endemic Areas Among Patients With Hepatitis C Treated With Direct-acting Antiviral Agents. Clin Gastroenterol Hepatol. 2017;15(1):132-6. doi: 10.1016/j.cgh.2016.06.023. [PubMed: 27392759]. 